\title{
DEVELOPING SPECIFIC CHINESE TEACHING MATERIAL FOR INDONESIA BASED ON A COMPARISON BETWEEN CHINESE AND ENGLISH TEACHING MATERIALS
}

\author{
印尼汉语国别教材的对比分析 \\ 一一《当代中文》（印尼语版）与《初级标准华语》为例
}

\section{Kelly Rosalin}

Chinese Department, Faculty of Humanities, Bina Nusantara University Jln. Kemanggisan Ilir III No.45, Kemanggisan - Palmerah, Jakarta Barat 11480 krosalin@binus.edu

\begin{abstract}
Teaching material is a foundation of language learning. It is also a very important tool in teaching and learning process. Especially for students who learnt in non-Chinese environment, during the learning process, they can only rely on teachers and teaching materials. Article was based on previous research about teaching methods. Article used two teaching materials that have Indonesian language translation Contemporary Chinese and Chuji Biaozhun Huayu. Besides, it compared the content and designed to analyze the similarities and differences of these teaching materials. Through the analysis, research gives solution in teaching materials design.
\end{abstract}

Keywords: Elementary Chinese teaching materials, comparative analysis, Contemporary Chinese, Chuji Biaozhun Ниауи

内容摘要

教材是语言学习的基础, 是对外汉语教学的最主要工具之一尤其是对于在非汉语环境中学习汉语的学 生。他们在学习汉语时, 只能依赖课堂教学环境中的教师和教材。笔者参考前人已有研究成果为基础, 选取两 套有印尼语注释的汉语教材--- 《当代中文 (入门级)》与《初级标准华语》, 对两套初级汉语教材的设计和 内容等方面进行对比研究, 分析两套教材的异同之处。通过对两套教材的比较, 提出一些自己对如何编好一部 针对印尼学生的初级汉语教材的看法。

关键词：初级汉语教材；对比分析；《当代中文 (入门级)》; 《初级标准华语》 
这两套汉语教材都是针对零起点汉语学习者学

吕必松（1996）认为教材是课堂教学的基础和 直接依据, 要提高课堂教学的质量, 就必须有理想的 教材。如果教材不理想, 甚至根本不适用, 就难以提 高课堂教学的质量。汉语教材具有一定的地位以及作 用, 它直接影响到汉语教学的质量并影响到学生对学 习汉语的积极性, 好的教材具有激发学生的学习兴趣 的作用, 便于学生吸收并了解教材里的内容。

在汉语教学的世界里, 汉语国别教材的编写和 开发越来越受到重视并显得更为重要与迫切。为了满 足各国对汉语的需求, 中国国内编写了一些国别化教 材。目前的状况是在印尼所使用的汉语教材大多数是 中国国内编写的汉语通用性教材。这些教材虽然不是 很适合印尼学习者学习, 但是要找到真正的适合印尼 学习者使用的印尼国别教材还存在一定的问题。主要 的问题就是这些教材还缺乏针对性。因此, 笔者选取 两部初级印尼汉语国别教材的综合课教材《当代中 文》与《初级标准华语》, 通过比较和评估, 从几个 方面对比评价, 分析出它们各自的长处和不足, 并总 结出它们所存在的问题。希望能够为印尼汉语国别教 材提供实用的建议和意见。

\section{内容}

\section{教材概况}

《当代中文 (入门级) 》多文种教材, 即在通 用性汉语教材的版本上作出多语种翻译的教材。此教 材已翻译成 43 个文种, 有英、韩、德、泰、日、印尼 等多种国家语言, 是目前世界上将出版语种最多权威 成人汉语教材并在 2009 年 12 月举行的孔子学院大会上 获得优秀国际汉语教材奖。这套教材是在对外国大学 实地考察的基础上, 充分考虑国外汉语教学环境的特 点编写而成的。《当代中文 (入门级)》多文种系列 (印尼语版) 是一套专门针对母语为印尼语的汉语零 起点学习者而设计。教材内容注意情节、情景的个性 化和人情味, 话题的情趣性和人性化, 通过特定的十 时实用交际任务把结构、功能、文化点有机结合起 来。这套教材的主要目标是培养学生对汉语的理解能 力和交际能力, 尤其听、说、读、写各项语言技能。 全套教材共有三本，包括《课本》、《练习册》与《 汉字本》。《当代中文》的教材体例是每个课的重 点、词语、课文、语音、语法、参考词语、文化点。 印尼语版的教材做了本土化的处理, 所以更适合印尼 汉语学习者的需求。本论文将选择《当代中文》入门 级多文种系列的课本和练习本进行详细地分析。

《初级标准华语》是专门为印尼学生编写的教 材。《初级标准华语》是2006年北京语言大学出版社 出版, 由宋燕坤编著, 这本教材特请从事华语教学 的印尼籍华语教师 Ibu E11y Romy 担任教材印尼语 翻译。专门针对印尼成年人学习汉语而编写的系列 教材, 作为国别教材, 其针对性和、专业性与实用 性十分突出。这套教材的主要目标是帮助学生掌握和 理解规范、自然、得体的语言表达, 并能够实现的有 效的交际。这套教材共有四本教材, 《初级标准华 语》第一册的教材体例是课文、生词、语法、注释、 学拼音、练习、你知道吗、挑战词汇、写汉字、轻松 时刻、北京的名胜。《初级标准华语》第二册和第三 册的教材体例没有学拼音的部分, 而北京的名胜部分 以扩展图片来代替, 但在第三册已没有写汉字的部分 了。本论文选择《初级标准华语》第一册、第二册与 第三册进行分析。
习汉语。两者都是中国国内编写的汉语教材。

《当代中文 (入门级)》与《初级标准华语》对比及 分析

本文是通过对教材的评估来对比这两套汉语教 材。首先, 我们应该知道什么是教材评估。李泉认为 教材评估就是根据特定的标准或原则对教材设计和实 施的成败得失、优势高下进行评议和估量。也就是评 估教材的成功之处、失误之处、不足之处，以及该有 的是否已有、已有的是否合理、合理的是否创新、创 新的是否突出, 等等。李泉还认为评估的范围和内容 可以多角度、多层次的全方位评估, 比如, 生词量及 重现率是否适当教材练习是否覆盖全部或主要教学内 容; 语法注释是否简明准确; 有无有配套材料及教师 手册等方面。

关于类似的研究, 徐蔚曾在《美国两部汉语教 材的对比分析》中, 把两套美国汉语教材主要以列表 的形式进行了对比，包括：（1）配套资料;（2）课 本的结构与编排; (3) 课文形式; (4) 语法出现形 式;（5）生词;（6）练习形式;（7）文化的呈现 方式及与课文的关系；（8）板式和装帧设计；（9） 汉字教学。本文想通过徐蔚所提出的这几个方面对两 套印尼国别教材进行对比分析。

配套资料

表1 配套资料

\begin{tabular}{lll}
\hline & 《当代中文 (入门级)》 & 《初级标准华语》 \\
\hline 学生资源 & 课本、汉字本、练习 & 第一册到第三册 \\
& 册和录音光盘2张、网 & \\
& 络教学资源 (http:// \\
& jxzy. Chinese. cn) & \\
&
\end{tabular}

从表中可看出《当代中文 (入门级)》比《初 级标准华语》的配套资料更为丰富。这两套教材都没 有教师手册, 而且《初级标准华语》没有附加辅助资 料。好的教材一定要有辅助资料 (录音光盘) 及教师 手册。教师手册作为教材体系中不可缺少的一部分, 教师手册是为帮助, 特别是青年教师更好地使用该教 材而编写的, 它对提高教学质量有着非常重要的作 用, 尤其是对于国外本土汉语教师来说, 教师手册是 作为教学的指南针, 帮助教师明确每课的教学目的, 起导向作用，便于教师做好授课的准备。

课本结构与编排

课本体例

表2 课本体例

\begin{tabular}{cc}
\hline 《当代中文 (入门级)》 & 《初级标准华语》 \\
\hline 前言 & 前言 \\
目录 & \\
范围和顺序 & 目录 \\
课文等 & 课文等 \\
附录: 人物表、语法术语表、 & 附录: 人物表、词类对照表、 \\
普通话声韵配合总表、印尼 & 课后练习参考答案、词汇表 \\
文课文、词语索引、语法项 & (包括专名) \\
目索引 & \\
\hline &
\end{tabular}


《当代中文 (入门级) 》的目录中有 “范围和 顺序”, 而《初级标准华语》的目录中只有话题。

\section{表3《当代中文 (入门级) 》}

范围和顺序范例（第一课）

\author{
第一课 您贵姓 \\ Pelajaran Ke-1 Siapa nama keluarga kamu? \\ Fonetik: modifikasi nada “不” \\ Tatabahasa: Pola kalimat sederhana 1: subye k+ kata kerja (+ objyek) \\ kata tambahan + kata kerja \\ kalimat tanya
}

从表格可以看出《当代中文 (入门级)》的目 录中包含了话题、印尼翻译、语音、语法等内容。这 套教材的附录内容也比较丰富, 它比《初级标准华 语》多的部分主要有普通话声韵配合总表、印尼文课 文以及语法项目索引, 而《初级标准华语》比《当 代中文 (入门级) 》多的部分主要是课后练习参考答 案。对于汉语学习者来说, 综合课的难点就在于它的 语法部分。因此, 笔者认为在附录中有 “语法项目索 引” 的部分是有利于学生复习语法部分。至于《初级 标准华语》附录中的 “课后练习参考答案” ，笔者认 为没有必要出现, 免得学生在做练习时, 参考后面的 答案。课后练习参考答案的部分应该放在教师手册 中。

课文的结构

表4 课文每一课结构

\begin{tabular}{ll}
\hline \multicolumn{1}{c}{ 《当代中文 (入门级)》 } & \multicolumn{1}{c}{ 《初级标准华语》 } \\
\hline 依次分别为: 范句、词语 (核 & 依次分别为: 课文、生词、语 \\
心词、补充词语)、课文、注 & 法、注释、学拼音 (第一册) \\
释、语音、语法、扩充词语、 & 练习、你知道吗、挑战词 \\
文化知识 & 汇、写汉字、轻松时刻、拓 \\
& 展图片 \\
\hline
\end{tabular}

语言教材一般由词汇、句型、课文和练习等部 分组成的。在《当代中文 (入门级)》教材中没有练 习部分, 是因为它把练习题集中在练习册上。与《 初级标准华语》相比, 《当代中文 (入门级) 》有一 个特点, 就是在每一课最前面有一个板块 “范句” “范句” 提示本课所要学的句型及主要内容, 引起 学习兴趣。因此, 在学习之前, 学生能够先了解, 这 一课大概学什么内容。而与《当代中文 (入门级) 》 相比, 《初级标准华语》有两个特点:第一 “轻松时 刻” , 这个部分能起到寓教于乐、加深记忆、活跃课 堂的效果, 通过游戏帮助学习者利用他们所学到的词 汇连接日常生活、社区和文化。例如: 以《初级标准 华语》第二册的第十九课 “比一比” 为例, 大家一起 列出蔬菜、水果的名称, 看有多少种, 然后比一比谁 记得最多; 第二 “拓展图片” ，每课的拓展图片中都 插入了一些有关中国风土人情的图片。这些图片与课 文内容相应, 也能够起到活跃课堂气氛的作用。

课文形式

表5 课文形式

\begin{tabular}{lll}
\hline & 《当代中文 (入门级) 》 & 《初级标准华语》 \\
\hline 课文出现形式 & 汉字上注拼音 & 第一册至第三册: 汉 \\
& & 字上都注拼音 \\
注释 & 汉字和印尼语 & 汉字、印尼语、拼音 \\
\hline
\end{tabular}

徐蔚认为课文注有拼音是有利有弊。一方面降 低了汉字认读的难度, 尤其是对一些学习比较困难或 者年级比较大的汉语学习者, 另一方面也容易培养成 汉语学习者对拼音的依赖性。

这两套教材的课文都注了拼音，笔者认为在《 初级标准华语》的第二册和第三册应该不必注拼音 了, 开始标注了调号。对于《当代中文 (入门级)》 应该前10课还可以注拼音, 第十一课开始应该只标注 了调号, 采取这种的方法, 能够让学生习惯认读汉 字，不依赖着拼音。而在 “注释” 部分也出现了文边 注，《当代中文 (入门级) 》的 “注释” 部分只是采 用汉字和印尼语来简单说明功能, 而在《初级标准华 语》的 “注释” 部分, 采用了汉字、拼音和印尼语说 明, 这样能够使学生更快地了解注释所解释的内容。

语法出现形式

表6 语法出现形式

\begin{tabular}{lll}
\hline & 《当代中文 (入门级)》 & 《初级标准华语》 \\
\hline 语法点说明 & 印尼语 & 汉语和印尼语 \\
例句出现形式 & 第一课至第8课: 汉字注拼音 & 第一册: \\
& 第9课至第12课: 汉字 & 第一课至第8课: 汉 \\
& 第13课: 汉字与印尼翻译 & 字、注拼音、印尼 \\
& 第14课至第20课: 汉字 & 语翻译 \\
& & 第九课: 汉字和印尼 \\
& 语翻译 \\
& 第二册与第三册: 汉 \\
& 字、注拼音、印尼 \\
& & 语翻译 \\
& &
\end{tabular}

《初级标准华语》的语法点说明是使汉语和印 尼语解释, 而《当代中文 (入门级) 》只用印尼语解 释。对于零起点的汉语学习者来说, 使用印尼语来说 明语法点是很有必要的, 利于学生的容易理解。

《当代中文 (入门级) 》的语法例句形式是相 当不错, 但是针对初级的汉语学习者, 在每个句子应 该有印尼语注释是比较好的。而在《初级标准华语》 的第二册和第三册, 应该把拼音删掉, 因为能够养成 学生对拼音的依赖性。

生词形式及数量

表7 生词形式及数量

\begin{tabular}{llll}
\hline & $\begin{array}{l}\text { 《当代中文 (入 } \\
\text { 门级)》 }\end{array}$ & $\begin{array}{l}\text { 《初级标准华 } \\
\text { 语》 }\end{array}$ \\
\hline 生词出现形式 & $\begin{array}{l}\text { 简体字、词性( } \\
\text { 简体字、繁体 }\end{array}$ \\
& & 音、印尼语译 & $\begin{array}{l}\text { 字、拼音、词 } \\
\text { 性、印尼语译 }\end{array}$ \\
\hline 生词数量 & 生词 (包括专名) & 685 (共22课) & 991 (共27课) \\
& 补充生词 & 296 & 250 \\
& 共计 & 981 & 1241 \\
\hline
\end{tabular}

《当代中文 (入门级)》的生词分为生词、专 名与补充词语三个部分, 而《初级标准华语》的生 词分为生词与专名两个部分, 该教材把补充词语放在 挑战词汇部分。这两套汉语教材对生词的解释简明易 懂, 采用了直接翻译法, 使用印尼语解释生词, 使学 生对词语理解起来更直观、更准确, 减少了因翻译的 不准确的问题给学生带来在应用上的错误引导。

从表格可以看出, 《初级标准华语》的生词量 词比《当代中文（入门级）》多，这两套教材对生 
词数量的控制比较合理, 《当代中文 (入门级)》教 材每课文的词汇量平均都控制在31个生词左右，而《 初级标准华语》教材每课文的词汇量平均都控制在 36 个生词左右 (不包含补充词语)。另外, 《初级标准 华语》还有一个比较突出的特点, 每一课的生词表都 同时列出了简体字和繁体字。根据Maharani在《印尼 华文教学中繁体字的使用情况及其未来的使用预测》 , “华文教学中使用繁简体汉字的选择要立足于教 学的主要目的, 她并建议使用简体汉字教学到一定程 度, 要到如繁体汉字教学, 使教学对象也懂繁体汉 字, 才利于教学对象阅读繁体汉字文献。”因此, 把 繁体字纳入生词表是有必要的。

练习形式

表8 练习形式

\begin{tabular}{|c|c|c|c|}
\hline & & 《当代中文 (入门级) 》 & 《初级标准华语》 \\
\hline \multirow[t]{2}{*}{$\begin{array}{l}\text { 课 } \\
\text { 本 } \\
\text { 练 } \\
\text { 习 }\end{array}$} & $\begin{array}{l}\text { 出 } \\
\text { 现 } \\
\text { 形 } \\
\text { 式 }\end{array}$ & & $\begin{array}{l}\text { 练习中出现的汉子都注 } \\
\text { 有拼音 }\end{array}$ \\
\hline & $\begin{array}{l}\text { 类 } \\
\text { 型 } \\
\text { 及 } \\
\text { 数 } \\
\text { 量 }\end{array}$ & 在课本没有练习部分 & $\begin{array}{l}\text { 语音练习 (10)；汉字练 } \\
\text { 习 (1) ; 词组练习 (7) } \\
\text {; 句子练习 (13) ; 综合 } \\
\text { 练习 (5) }\end{array}$ \\
\hline $\begin{array}{l}\text { 练 } \\
\text { 习 } \\
\text { 册 }\end{array}$ & $\begin{array}{l}\text { 类 } \\
\text { 型 } \\
\text { 及 } \\
\text { 数 } \\
\text { 量 }\end{array}$ & $\begin{array}{c}\text { 语音练习 (4); 词组练习 } \\
\text { (3) ; 句子练习 (11) ; } \\
\quad \text { 综合练习 (4) }\end{array}$ & 没有练习册 \\
\hline $\begin{array}{l}\text { 汉 } \\
\text { 字 } \\
\text { 练 } \\
\text { 习 } \\
\text { 册 }\end{array}$ & $\begin{array}{l}\text { 类 } \\
\text { 型 } \\
\text { 及 } \\
\text { 数 } \\
\text { 量 }\end{array}$ & $\begin{array}{c}\text { 汉字练习 (12) ; 拼音练 } \\
\text { 习 (2) ; 词组 (2) ; 句 } \\
\text { 子练习 (1) }\end{array}$ & 没有汉字练习册 \\
\hline
\end{tabular}

教材中的练习部分对学习和教学起着十分重要 的作用。教师通过练习可以了解学生的学习情况。《 当代中文 (入门级) 》与《初级标准华语》教材的练 习部分都已经涉及到听说读写四项技能的训练, 题型 丰富, 有语音练习、汉字练习、词组练习、句子练 习、综合练习。这两套教材的练习是由死到活以标 准, “死” 是指机械练习或形式练习, 如: 语音练 习（辨析声母、辨析韵母、重复语音等）, “活” 是 指活用联系，如：综合练习（说一说、描写图片、 回答问题等）。《当代中文 (入门级)》有一个比 较突出特点, 这本教材设计了拼音练习。针对零起点 的学生, 拼音练习是非常重要, 零起点的学生刚开始 学习汉语时, 不认字, 因此, 拼音对他们起着十分重 要的作用。《初级标准华语》从第一册至第三册的练 习中出现的汉字都注拼音, 笔者认为第二册开始, 练 习中的汉字应不必注拼音, 助于学生认字的能力。《 当代中文 (入门级)》的练习册的提示题都只使用印 尼语, 笔者认为练习的提示题应该有汉字与印尼语, 这样才能让学生逐步地熟悉汉语。

文化呈现方式

《当代中文 (入门级) 》每一课后有 “文化知 识” , 用印尼语介绍一些跟课文相关的文化知识, 比 较简短。与之相比, 《初级标准华语》每一课都有 “ 你知道吗”，“你知道吗 “, 这部分是介绍中国文化 知识并使用汉字与印尼语来介绍, 内容比较丰富, 几
个课的 “你知道吗 “配有真实的图片, 以第一册的 第七课的 “你知道吗 “为例，介绍关于长城的烽火 台, 在 “北京的名胜 “的部分配有一张烽火台的真实 图片。但《初级标准华语》的文化知识跟课文内容无 关。笔者认为在文化知识的部分所介绍的中国文化知 识应与课文内容有相应的联系。每个文化知识也需要 配有相关的真实图片。

\section{版式和装帧设计}

赵金铭拟定的对外汉语教材评估表，其中一个 的评估的项目是对教材的形式的标准，教材的形式主 要设计版式和装帧设计。赵金铭对版式和装帧设计 主要的要求是教材开本合适，使用方便、插图数量适 当, 与内容配合紧密、版面活泼新颖, 吸引学习者以 及教材内容适用不同字号编排。

《当代中文 (入门级) 》与《初级标准华语》 这两套教材已经符合赵金铭所提出的标准。《当代中 文 (入门级) 》与《初级标准华语》采用两色印刷, 每一页页眉列出可序号及课文名称，方便使用。《初 级标准华语》的插图数量比 《当代中文 (入门级)》 多，但两套教材在课文或者练习部分所采用的图片不 是真实图片, 《初级标准华语》只在 “拓展图片” 的 部分与第三册采用真实图片。

笔者认为如果图片来源于真实图片，如真实生 活场面, 能够使学生感到很自然也很亲切, 能够引起 学生对教学内容的兴趣, 而且所插入的图片也要与教 学内容相关。

汉字教学

印尼是属于非汉字圈的国家，对于印尼汉语学 习者来说, 要学习并掌握汉字并不是很简单的事情。 汉字是表音和表义的文字，不是像印尼文字是拼音文 字。因此, 在汉语教材必须重视汉字教学, 尤其是针 对零起点与初级学生的汉语教材, 才能为汉语学习者 在书写汉字打好基础。

《初级标准华语》没有专门设计汉字教学的部 分, 只设计汉字练习, 就是写汉字, 只有在第一册和 第二册。而《当代中文 (入门级)》在汉字本是专 门针对汉字教学而编, 不仅介绍了汉字的基础知识、 包括汉字结构、偏旁、壁笔顺等, 而且在汉字本也 有许多涉及到汉字教学的练习, 汉字的练习形式也是 多样，如：写汉字、看拼音写汉字、补上遗漏的笔 画、猜一猜汉字的组合、写出含有下列部件的汉字等 等。可以看出来, 《当代中文 (入门级)》的编者很 注重汉字教学。

结论

通过以上分析和比较, 可以看出《当代中文 (入门级) 》与《初级标准华语》各有长处和短处。 笔者通过以上的对比分析得出在为印尼编写汉语教材 要考虑到九个方面。第一, 在配套资源方面, 一定要 有辅助资料（录音光盘）及教师手册。第二，在课本 结构和编排方面, 教材的目录中需要有范围和顺序, 使学生更详细、清楚地了解通过这本教材他们会学到 什么。第三, 从课文形式方面看, 初级教材的课文内 容的前十课或第一册都能注有拼音以及印尼翻译，降 低了汉字读写难度并让学生更容易了解课文内容, 但 从十一课或第二册开始不必再注拼音, 而需要标注了 调号与印尼语翻译。第四，教材的语法形式应使用汉 
语和印尼语说明。第五, 生词数量要一定的控制上, 每个课文的生词量要平均, 生词表同时列出简、繁体 字, 更适合印尼学生。第六、练习形式要多样并针对 印尼学生学习汉语的难点作为出发点。第七、从课本 对文化知识的处理上, 文化知识的内容要丰富, 如果 能够对比印尼与中国的文化是比较好。第八, 从版式 和装帧设计看, 教材所有的插图应采用真实土图片, 才能够引起学生的兴趣。第九, 因为印尼是非汉子圈 的国家, 针对印尼学生的汉语教材应更注重汉字教学 方面。

\section{参考文献}

李泉. (2006). 对外汉语教材研究. 北京: 商务印书 馆.

徐蔚. (2011). 美国两部汉语教材的对比分析一 《 中文天地》和《新实用汉语课本》。云南师范 大学学报, 9 (2) : 20-26.

周蕾. (2009). 泰国高校初级汉语精读课教材对比 研究——以《汉语教程》与 《基础汉语》为 例. 硕士学位论文. 厦门: 厦门大学.

Maharani. (2008). 印尼华文教学中繁体字的使用情况 及其未来的使用预测. 汉字运用与国 (华) 语 文教学国际学术研讨会论文集.

宋燕坤. (2006). 初级标准华语 (第一册). 北京：北 京语言大学出版社.

宋燕坤. (2006). 初级标准华语 (第二册). 北京：北 京语言大学出版社.

宋燕坤. (2007). 初级标准华语 (第三册). 北京：北 京语言大学出版社.

吴中伟. (2010). 《当代中文》入门级 (课本). 北 京: 华语教学版社.

吴中伟. (2010). 《当代中文》入门级（练习册）. 北 京: 华语教学版社.

吴中伟. (2010). 《当代中文》入门级 (汉字本). 北 京: 华语教学版社. 